\title{
Modern scaffolding strategies based on naturally pre-fabricated 3D biomaterials of poriferan origin
}

\author{
Dmitry Tsurkan ${ }^{1} \cdot$ Marcin Wysokowski ${ }^{2,3} \cdot$ laroslav Petrenko ${ }^{2} \cdot$ Alona Voronkina $^{4} \cdot$ Yuliya Khrunyk $^{5,6} \cdot$ Andriy Fursov $^{2}$. \\ Hermann Ehrlich ${ }^{2,7}$
}

Received: 4 April 2020 / Accepted: 17 April 2020

(C) The Author(s) 2021

\begin{abstract}
Modern scaffolding strategies include two key ways: to produce requested 3D constructs from corresponding precursors using technological tools, or simply use naturally already pre-fabricated scaffolds if they originate from renewable sources. Marine sponges inhabit oceans since the Precambrian. These ancient multicellular organisms possess a broad variety of evolutionary approved and ready to use skeletal structures, which seem to be well applicable as 3D scaffolds in diverse fields of modern bioinspired materials science, biomimetics and regenerative medicine. In this review, most attention is paid to biosilica-, chitin-, and spongin-based scaffolds of poriferan origin with respect to their potential use.
\end{abstract}

Keywords Biomimetics $\cdot 3 \mathrm{D}$ scaffolds $\cdot$ Biological materials $\cdot$ Biosilica $\cdot$ Chitin $\cdot$ Spongin

\section{Introduction}

Both modern structure-based technologies and tissue engineering urgently require large-scale three-dimensional (3D) manufacturing approaches to create appropriate technologies as well as biologically active 3D scaffolds, respectively.

Marcin Wysokowski

Marcin.Wysokowski@put.poznan.pl

$\triangle$ Hermann Ehrlich

Hermann.Ehrlich@esm.tu-freiberg.de

1 TissueGUARD GmbH, 01217 Dresden, Germany

2 Institute of Electronic and Sensor Materials, TU Bergakademie Freiberg, 09599 Freiberg, Germany

3 Faculty of Chemical Technology, Institute of Chemical Technology and Engineering, Poznan University of Technology, 60965 Poznan, Poland

4 Department of Pharmacy, National Pirogov Memorial Medical University, Vinnytsya 21018, Ukraine

5 Department of Heat Treatment and Physics of Metal, Ural Federal University, Mira Str. 19, Ekaterinburg, Russia 620002

6 The Institute of High Temperature Electrochemistry of the Ural Branch of the Russian Academy of Sciences, Akademicheskaya Str. 20, Ekaterinburg, Russia 620990

7 Center for Advanced Technology, Adam Mickiewicz University, 61614 Poznan, Poland
Consequently, 3D scaffolds for technological applications must possess requested structural and mechanical cues at nano-, micro- and macroscale. Moreover, 3D constructs used for tissue engineering must be bio- and eco-compatible as well as have specific biological, immunological and physicochemical properties. Only those scaffolds, which can be suitable to support optimal cell growth, differentiation and proliferation [1], have a potential to be applied in diverse fields of modern biomedicine.

The use of natural polymers and biocomposites to substitute those of artificial origin seems to be the best strategy to produce 3D scaffolds. However, this approach is connected with numerous preparative steps such as dissolution of biopolymers in special liquids, mechanical disruption, chemical leaching under harsh conditions, thermally induced phase separation, or supercritical drying with the aim to obtain corresponding powders, flakes, etc., for example, from cellulose, or chitin. These structures of biological origin should be further employed in equipment-based technologies resulting in the formation of $3 \mathrm{D}$ constructs. The establishment of such scaffolding strategies is rather challenging and faces many disadvantages, which can be a serious drawback in terms of cost and profitability for future applications.

Recent focus in biomaterials inspired science and biomimetics has been concentrated on already existing, naturally prefabricated skeletal structures of marine origin with 
unique 3D architecture [2]. Special attention is currently paid to sponges (Porifera) as a renewable source of naturally pre-designed 3D structured biological materials [3-5]. For the first time, we represent here an analytical study on three types of 3D scaffolds derived from marine sponges (Fig. 1) with respect to their technological and biomedical perspectives.

\section{Siliceous skeletal frameworks}

One of the superior sources of inspiration in the development of novel 3D composites is the evolutionarily optimized 3D biosilica-based skeletons of glass sponges (Hexactinellida) $[6,7]$ which represent a successful evolution in nature [8]. These hierarchically structured skeletons have been designed by living organisms over the last $600 \mathrm{Myr}$ for efficient filtration of feed from surrounding seawater. Siliceous skeletons of sponges are lightweight structures that display an astonishing variety of complexity and diversity in size and shape due to their ability to produce silica-based spicules of triaxonic (cubic) and mostly hexactinic symmetry or constructs derived from them by reduction of primary rays or terminal branches added to the ends of primary rays (Fig. 2) [9]. These complex cellular biosilica structures reaching in some species up to $2 \mathrm{~m}$ in size $[2,7,10,11]$ are characterized by sophisticated hierarchical organization, in which each hierarchy level is tuned to specific function. The fusion of properties of all of these levels ensures outstanding energy dissipation and resistance to mechanical strain [12-16]. Surprisingly, fabrication of such hierarchical complex glass structures still seems to be far beyond the reach of current human technology [17]. Numerous studies of glass sponges skeletons suggest that the unique fracture toughness results from the spicules cylindrical layered architecture. However, Monn et al. [18] discovered that while interfacial fracture does improve the toughness of the cylindrically layered beam, its impact is relatively small compared to the arrest and re-nucleation mechanism that occurs in the planar layered beam [18]. This finding is questioning this theory and shows that the understanding of the relationship between layered architectures and toughness enhancement is not yet complete. Controlled, slow dissolution of spicules of various hexactinellids reveals that the silica layers also contain a fibrillar organic matrix similar to the interlayers, which probably serves both as a scaffold within the layers and glue between them $[19,20]$. Therefore, a detailed understanding of the link between organic-inorganic interface and the toughness of bio-silica skeletons of sponge origin is crucial for the biomimetic design and engineering

\section{Modern scaffolding strategies based on naturally pre- fabricated 3D biomaterials of poriferan origin}
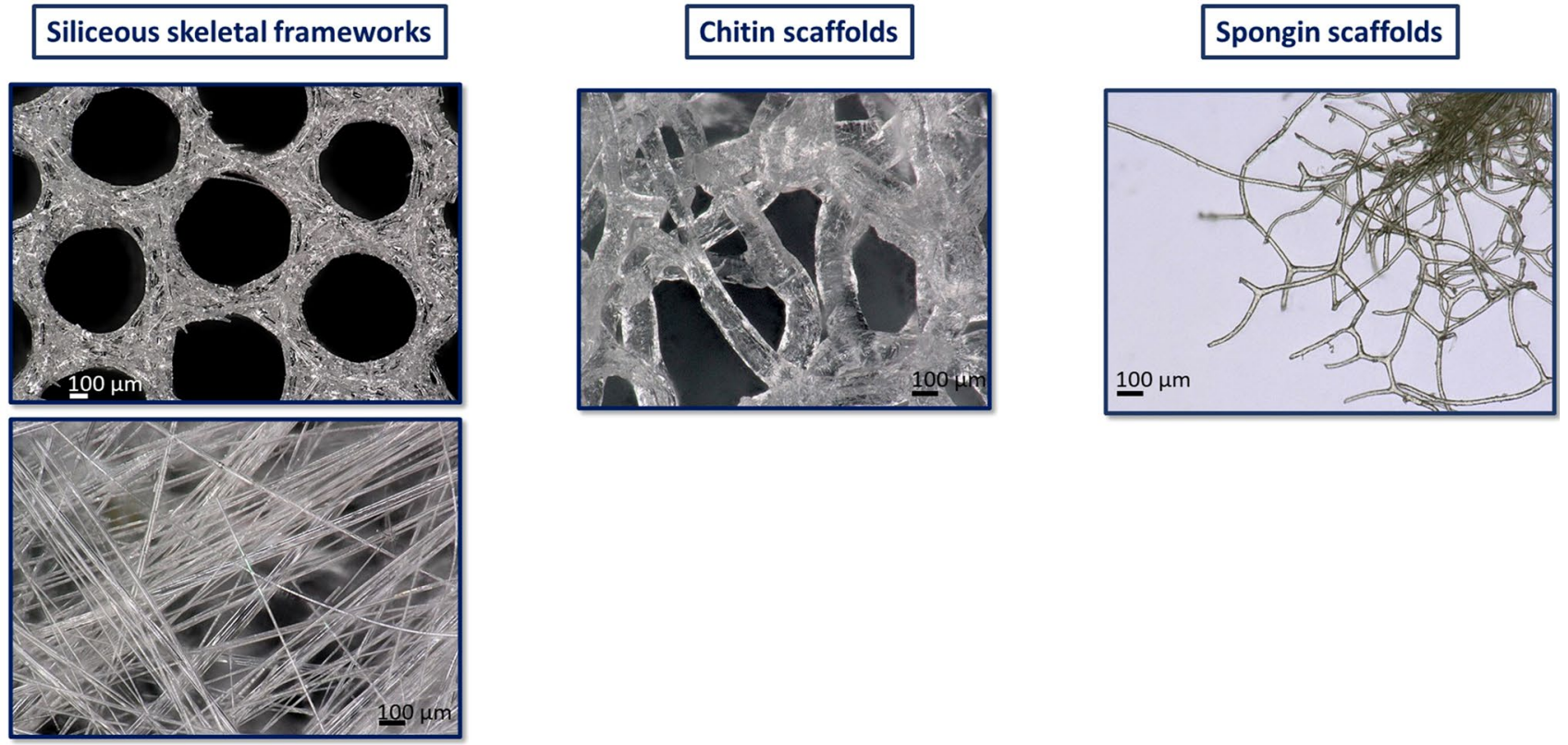

Fig. 1 Sponges possess a unique ability to produce hierarchically structured 3D scaffolds made of chitin, spongin, or silica-based biocomposites of both biopolymers. Due to the cultivation of sponges, they represent a unique renewable source of such 3D constructs 

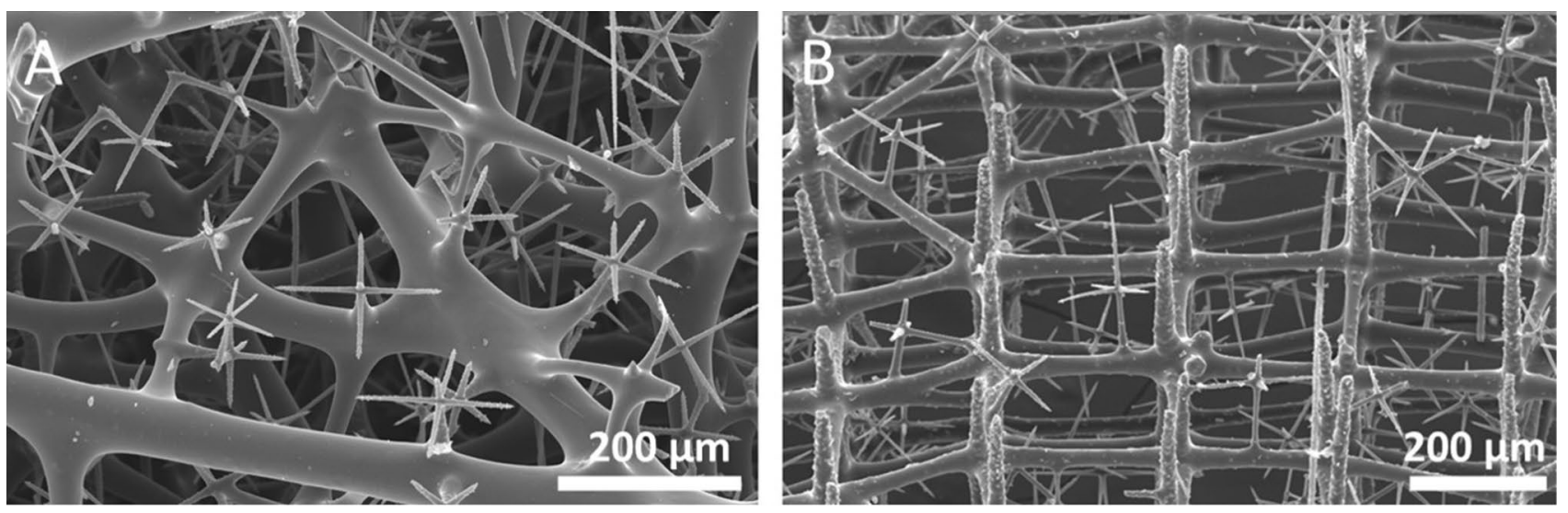

Fig. 2 Glass sponges (Hexactinellida) represent broad diversity $(\mathbf{a}, \mathbf{b})$ of unique siliceous 3D structured skeletal frameworks

of novel materials [21, 22], by means of existing tools and manufacturing schemes, for the targeted application in new $3 \mathrm{D}$ open-celled products to be used for human endeavors $[13,18]$. Over the last decades numerous research groups analyzed the organic constituents involved in spiculogenesis and supporting formation of sophisticated glass sponge constructs. According to the present state of art, four different organic templates that may be involved in biosilicification in glass sponges were isolated and proposed: silicateins [17, 23], glassin [24], collagen [25] and chitin [26, 27]. The silicatein- and glassin-based hypotheses are in conflict with the proposed role of collagen and chitin as alternative templates in spicule formation in glass sponges (for details please see [7]) and became a serious bone of contention between various research groups. Definitively it is time to overcome this continuing disagreement, finally join forces and find the link, which connects all proposed pathways into one, yet unrecognized mechanism.

The latest developments in micro-computer tomography, 3D additive manufacturing techniques and finite element simulation capabilities may pave new avenues to mimic design features observed in bio-siliceous skeletons of marine sponges and develop new structurally efficient engineering architectures [13]. For the first time, Brown et al. [13] reported that $3 \mathrm{D}$ data extracted from the $\mu \mathrm{CT}$ of the sponge skeleton can be used to create accurate FE models and replication through 3D printing. Recently, based on morphological characteristics of glass sponges, two novel bio-inspired thin-walled lightweight structures were proposed and manufactured employing stereolithography 3D printing technology by Li et al. [8]. Such proposed structures, inspired by glass sponges, can be used to create lighter structures with less material maintaining, however, exceptional mechanical properties, which has a great potential for the engineering applications, such as aerospace [8]. This definitively brings us closer to the biomimicry of hierarchical complex glass structures, but also clearly shows how nature is ahead of our most advanced technologies. Nevertheless, we still can benefit from the remarkable structural advancements of natural glass sponge scaffolds by simply applying them as siliceous frameworks in various technologies. Indeed, the sources of died glass sponge skeletons located on the sea bottom in the Arctic and Antarctic regions are very rich [2].

Open-cell foams offer remarkable properties such as a large external surface area, a high mechanical strength and a high porosity; moreover, they guarantee accessibility to the active centers and a low resulting pressure drop [28-30]. Open-cell sponge-like catalysts were applied for Fischer-Tropsch synthesis [31], water disinfection by photocatalytic process [32], partial oxidation of methanol [33], $\mathrm{CO}_{2}$ methanation [34] and many others. Naturally pre-fabricated siliceous skeletal frameworks of glass sponges seem to have all the necessary properties including high thermal and chemical stability as well as defined pore size and cell geometry ensuring good mass transport, which makes them ideal candidates for catalyst support. Due to the presence of $\mathrm{Si}-\mathrm{OH}$ groups, they can be easily functionalized with various catalytically active nanoparticles. Additionally, skeletons of glass sponges possess exceptional optical properties $[27,35,36]$ that ensure effective light distribution and make them suitable to operate in a wide range of conditions of photocatalytic reactions. Bio-inspired transparent glass sponges, prepared by polymer replica technique, were recently reported to be a new class of substrates for $\mathrm{TiO}_{2}$ immobilization, which could be used as heterogeneous photocatalysts in water and air decontamination [32]. Therefore, we believe that evolutionarily optimized siliceous frameworks have great perspectives to serve as templates and as bioinspiration in fabrication of new catalyst supports.

Biosilica and silica-based biomaterials are excellent biocompatible materials having particularly beneficial effects on bone and cartilage healing due to their capacity to increase mineralization (formation of mineralized calcium phosphate nodules or hydroxyapatite) [37-40]. 
For this reason, they are proper bone filling materials used to develop tissue-engineering scaffolds. Therefore, it is not surprising that the fabrication of highly porous, threedimensional silica-based scaffolds for tissue engineering has received broad attention over the last decades [41, 42]. However, producing silica fibers (with controlled lengths and submicron diameter), as well as 3D structures, is still a challenging task [42]. These limitations are being tackled by using natural materials. Martins et al. [40] imply that the astonishing body architecture of naturally prefabricated siliceous scaffolds of marine sponges can be efficiently applied in tissue engineering, especially as a support for the development of bone replacement materials. The siliceous skeletons of sponges possess superbly organized 3D hierarchical architecture with adequate interactive surface for cell attachment, growth, and differentiation that could be predesignated for the seeding of human stem cells [40]. These skeletons provide an exceptional 3D porous and interconnected support for the cells, too. Furthermore, information on their structure can be used in the prototyping and fabrication of synthetic tissue-engineering scaffolds, offering the biochemical clues provided by their composition [40]. Mammalian bone is a well-known example of a structure composed of collagen and hydroxyapatite. Likewise, highly flexible basal spicules of some glass sponges are based on silicified collagen, though they are evolutionary much older [20, 25]. This suggests that the evolution of silica and bone skeletons share a common origin with respect to collagen as a unified template for biomineralization. The bioinspired combination of silica with fibrillar collagen enabled the preparation of monolithic scaffolds suitable for long-term cell culture experiments, confirming that the silica-collagen xerogels support adhesion, proliferation, and osteogenic differentiation of human mesenchymal stem cells in vitro [21]. Osteoblast/osteoclast co-culture experiments indicated that biphasic silica-collagen xerogel supports adhesion, differentiation, and proliferation of osteoblasts and allows osteoclastogenesis as well as cell-mediated degradation directly on the xerogels $[38,43]$.

In summary, the siliceous frameworks of glass sponges still have numerous secrets to reveal. We all realize that revealing of these secrets will be definitively a breakthrough for modern materials science and engineering. Therefore, to fully understand them we should adapt truly multidisciplinary and multi-scale approaches, but more importantly, scientific community should start collaborating instead of competing, and stop forcing partial truth rather than to strive to meet the full knowledge. Nevertheless, at this stage we can easily benefit from glass sponges unique structures and use them as scaffolds in the creation of advanced catalysts or bone substitutes.

\section{Chitin scaffolds}

Chitin is an evolutionarily ancient and superior scaffolding biomaterial which offers nanofibrous framework for mechanical support and imparts to the skeletons of invertebrate species and biological systems across the globe [2, 44-48]. Chemically, chitin is an insoluble, nanocrystalline linear polysaccharide of $\beta$-1,4-linked $N$-acetylglucosamine units that occurs in three polymorphic forms, namely alfa-, beta- and gamma-chitin [49]. A detailed historical overview on the 220 years of chitin research is excellently represented in the recent review article by Grégorio Crini [50]. Since the discovery of chitin by Odier, most scientific attention has been paid to its structure, origin, biosynthesis, chemistry and chemical modifications. Chitin is known to be nontoxic, biodegradable, biocompatible, antioxidative, antimicrobial, and anti-oncogenic biopolymer $[49,51]$. Therefore, chitin is now considered to be a superior candidate for the development of advanced functional materials $[46,51]$ inspiring scientific community to develop chitin-based 3D scaffolds for a broad spectrum of applications [52]. Nevertheless, the synthesis of twoas well as three-dimensional chitinous structures is still a major challenge, which requires sophisticated processes and unit operations [46, 53-55]. Therefore, the discovery of naturally occurring, morphologically defined chitinbased skeleton of sponge origin should be considered as a milestone in chitinology.

First discovery of chitin-based scaffolds in Verongida sponge skeletons in 2007 [56] was intriguing from evolutionary point of view. It indicates the presence of this biopolymer several hundred million years before the appearance of chitin in arthropod skeletons. Later, in 2013, we succeed in confirmation of it presence also in fossilized skeleton of 505-MYR-old demosponge Vauxia gracilentia [57]. Over the last 13 years a systematic monitoring of chitin in diverse sponges is still in progress. Up to today, this polysaccharide has been found in 23 species including freshwater $[58,59]$ as well as marine sponges [60-70]. Discovery of chitin in sponge skeletons implies that this biomolecule plays the role of a versatile template for biomineralization in both calcification and silicification reactions, simultaneously [45]. Additionally, it has been found that in case of sponges of the Verongiida order, isolated chitin resembles the size, shape, porosity as well as $3 \mathrm{D}$ architecture of originally occurring sponges, which can be successfully cultivated under marine farming conditions. We can speak about the existence of naturally prefabricated, micro-tubular, ready-to-use 3D chitinous scaffolds and use corresponding demosponges as exceptional and renewable source of them. From this point of view it was necessary to develop ultra-fast methods for 
the isolation of chitinous scaffolds from marine sponges. Klinger et al. [69] developed a method based on microwave irradiation (MWI) that is cost-effective, reduces the use of aggressive chemicals and decreases isolation time from 5 days (classical method) to $1 \mathrm{~h}$, without negative impact on the crystallinity, acetylation degree and molecular weight.

The extraordinary structural features combined with the biocompatibility and mechanical properties of 3D chitinous scaffolds from marine sponges (Fig. 3a) render them ideal for diverse biomedical applications, especially for stem cell-based tissue-engineering (Fig. 3b) [71]. Mutsenko et al. [72, 73] reported that "ready-to-use" tissue-engineered products based on chitin isolated from Ianthella basta and Aplysina aerophoba demosponges possess remarkable biocompatibility and cytocompatibility with human bone marrow-derived mesenchymal stromal cells in vitro. Cells cultured onto chitin scaffolds were able to differentiate into the chondrogenic, osteogenic and even adipogenic lineages, respectively $[72,73]$. Recently, we evaluated the potential of the 3D chitin scaffolds isolated from A. aerophoba; $I$. flabeliformis and I. labyrinthus demosponges for cell culture and tissue engineering by using human induced pluripotent stem cell-derived cardiomyocytes (iPSC-CMs) [74, 75]. Our experiments using iPSC-CMs revealed strong interaction of iPSC-CM layers with the chitin fibers for a longer culture period. Thus, naturally pre-designed 3D chitin scaffolds of poriferan origin may be compatible for the application in advanced cell culture models and cardiac tissue engineering.

High thermal stability (even up to $360{ }^{\circ} \mathrm{C}$ ) is a key feature of chitin-based scaffolds of poriferan origin, which opens the gate for the utilization of this biopolymer as structural scaffolds in extreme biomimetics [76]. This has provided visionary new opportunities for materials science, drawing the attention of the broader scientific community to the applications of structural biopolymers in hydrothermal systems according to the Extreme Biomimetics concept [77, 78]. Furthermore, these unique 3D tubular constructs
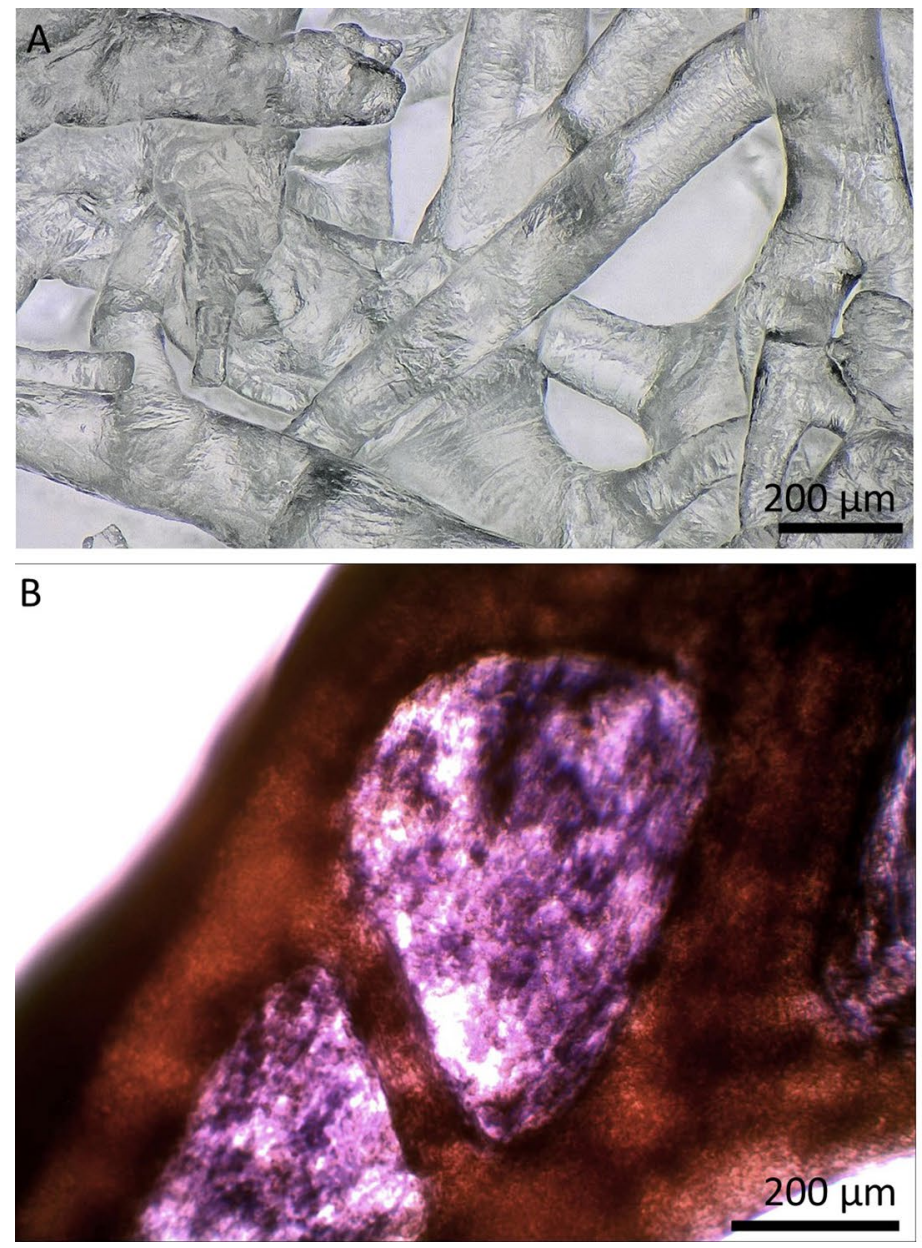

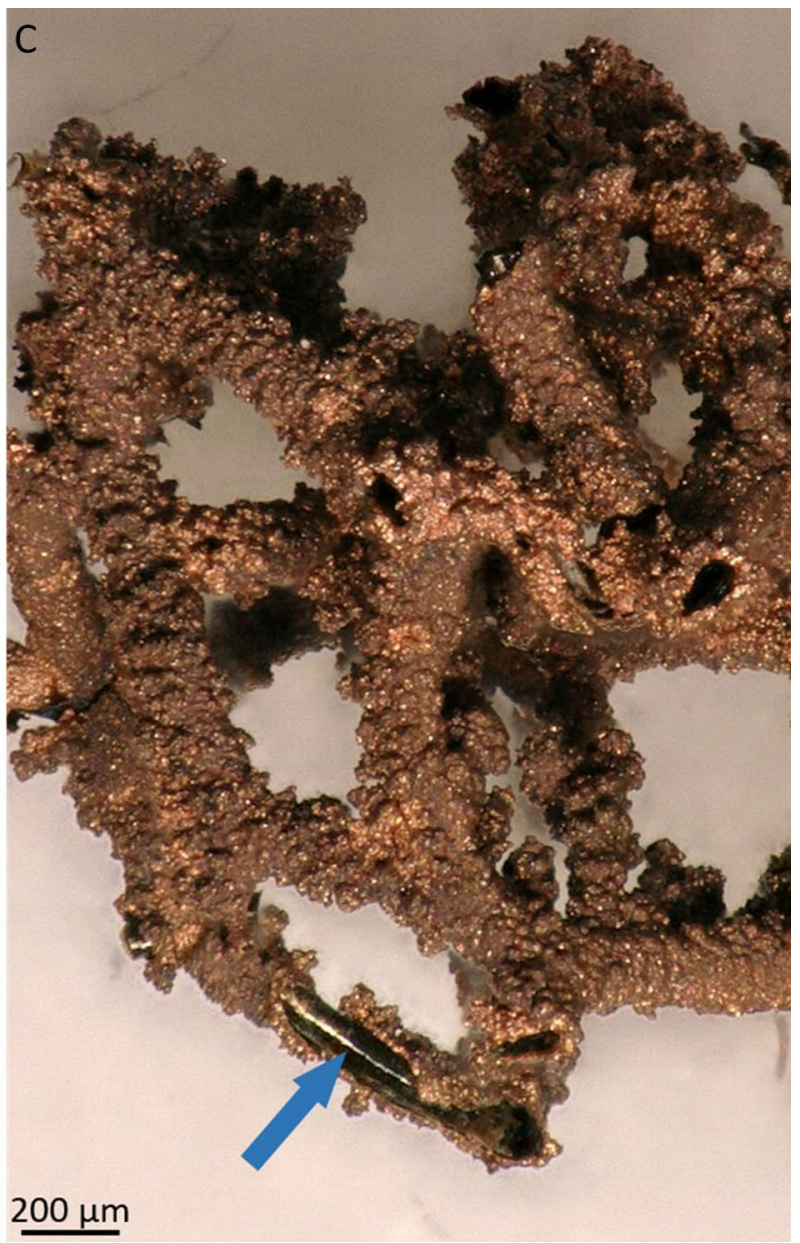

Fig. 3 Naturally pre-fabricated 3D chitinous scaffolds, which can be isolated from diverse demosponges of Verongiida order (a) have already found applications in tissue engineering of human mesenchy- mal stromal cells (b) as well as templates (c, arrow) for construction of copper-based 3D catalysts using electroplating 
possess the capacity for saturation with any kind of inorganic precursor solution (Fig. 3c). Recent studies have revealed that such renewable $3 \mathrm{D}$ chitin-based constructs can be used as naturally prefabricated thermostable biopolymeric scaffolds with 3D architecture for the nucleation and growth of a wide range of novel nano-organized $\mathrm{SiO}_{2}-$ [79], $\mathrm{Fe}_{2} \mathrm{O}_{3}-$ [80], $\mathrm{ZnO}-, \mathrm{ZrO}_{2-}$ [77], $\mathrm{GeO}_{2^{-}}$[81], POSS- [82] and multiphased $\mathrm{TiO}_{2} / \mathrm{ZrO}_{2}$-based [83] composites, which was inspired by biomineralization phenomenon occurring in hydrothermal vents. Indeed, biocomposites with such unusual properties are attractive for modern technological applications.

\section{Spongin scaffolds}

The biochemistry, structural features and functionality of spongin as a halogenated scleroprotein of keratosan demosponges (Fig. 4a) are still paradigms, which have been recently discussed by Jesionowski et al. [5] and Ehrlich [2]. Spongin, the main fibrous component of the keratosan demosponges skeletons, belongs to the collagen suprafamily [4, 84], which concentrates attention of wide scientific community due to its extraordinary, hierarchical, nanofibrillar organization [85, 86] and distinctive biomechanical performance [87]. The structure of collagen-like spongin has multiple levels comprising single fibers up to $100 \mu \mathrm{m}$ of thickness, composed of nanofibers, which are combined into complex hierarchical highly porous 3D networks (Fig. 4b) exhibiting specific structural and mechanical properties [4]. However, in contrast to collagen, spongin chemistry is made very complex due to the presence of diverse halogens (I, Br), which contribute to its exceptional enzymatic and thermal resistance. As reviewed by Szatkowski et al. [88] and Jesionowski et al. [5], from the eighteenth century commercial sponging-containing bath sponges were valued in medicine, for example, fragments of sponge skeleton were used as small prostheses in early "plastic surgery" [5]. Surprisingly, despite all these remarkable features, the US \$20 million annual market, and extensive marine farming of bath sponges worldwide, in these days, large-scale applications of spongin are generally limited to cosmetic uses [5]. However, recently the scientific community is wisely turning back to remarkable body architecture of spongin-based scaffolds, which are now actively reported in diverse modern applications.

Green et al. [89] confirmed the biomedical potential of spongin scaffolds to deliver bone morphogenic proteins and its advantageous architecture for human osteoprogenitor cell attachment, growth, differentiation, and ultimately mineralization. Additionally, authors reported that the primary chondrocytes, primary adipocytes, and promyoblasts were found to attach and aggregate in an analogous manner within sponginous skeleton [89]. Sponginous skeletons possess the structure that provides appropriate spatial organization of cells into bone tissue morphology and facilitates maximal invasion of cells and bone tissue essential for reconstruction, together with conduits appropriate for blood vessel anastomosis [90]. Moreover, authors proved that spongin is able to adsorb and release a recombinant human bone morphogenetic protein-2 with induced expression of alkaline phosphatase in a myoblast cell line [89]. Correspondingly, a hypothesis that spongin is effective in activating bone mineralization was raised by Kim et al. [90]. Authors proved with strong evidence that spongin increased alkaline phosphatase activity, collagen synthesis and osteocalcin secretion in osteoblastic cells in vitro. Interestingly, they demonstrated that spongin possesses anti-inflammatory effect by the inhibition of inflammatory mediators (such as TNF- $\alpha, \mathrm{IL}-1 \mathrm{~b}$, and $\mathrm{PGE}_{2}$ in macrophage cells) production [91]. Above-mentioned studies indicate that spongin scaffolds provide useful models for the future designs of
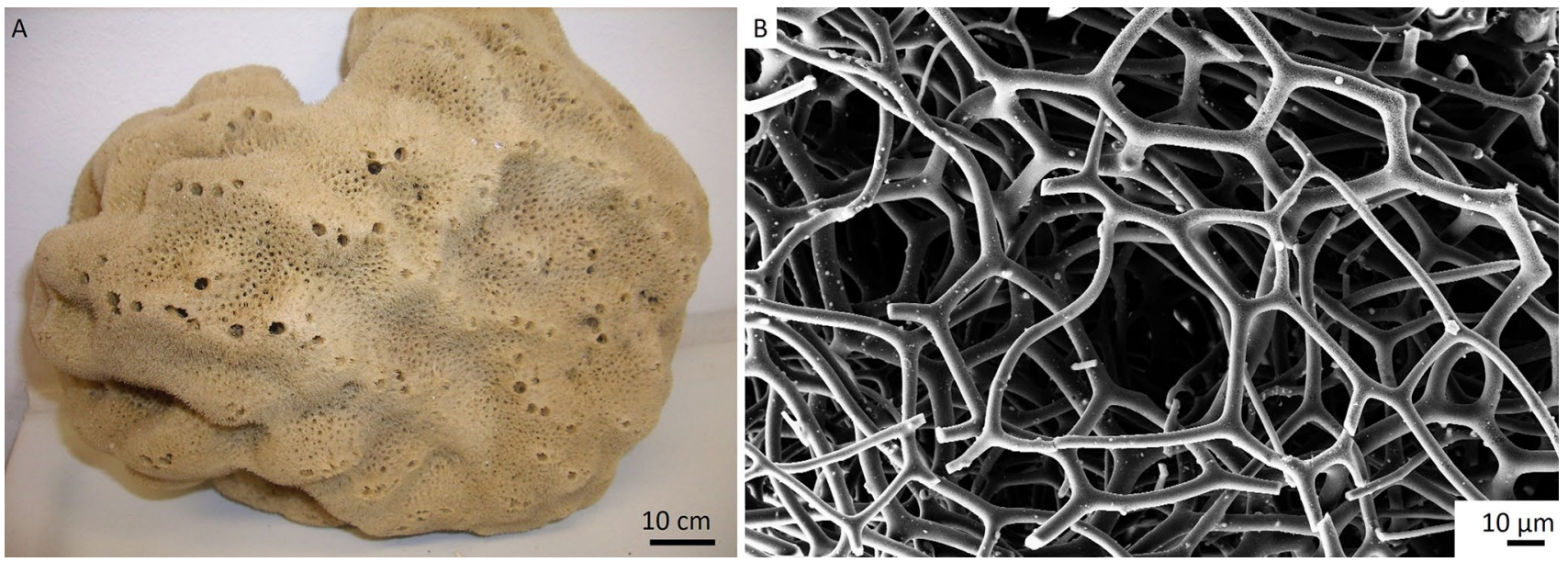

Fig. 4 Commercial keratosan demosponges a represent renewable source of unique spongin-based scaffolds $\mathbf{b}$ with microporous 3D architecture 
tissue-engineering scaffolds due to their collagen-based, open porous fiber architecture, anti-inflammatory effect and the ability to adsorb and release functional growth factors. In addition to that, the use of spongin as the structural templates for the fabrication of ceramic-based scaffolds for bone regeneration has been also reported [5]. In fact, scientists were able to produce tissue engineered bone scaffolds from spongin coated with hydroxyapatite [92], 45S5 Bioglass ${ }^{\circledR}$ [93] as well as from calcined spongin. In comparison with polymer (polyurethane foam, in this case) replication technique, spongin-based templates showed better mechanical properties due to a decrease in porosity, but without affecting the pores interconnectivity (higher than 99\%) [92, 93]. Parisi et al. [94] and Fernandes et al. [95] proposed the development of spongin-hydroxyapatite and spongin-biosilicate composites, respectively. Obtained materials possess improved performance of the graft for bone regeneration applications. Therefore, the replication of spongin structural organization allows for the reliable and repeatable biomimetic production of ceramic and composite scaffolds with the necessary features for viable bone substitute materials.

Besides applications in the biomedicine, spongin-based scaffolds have been functionalized with various phthalocyanines and exhibit profitable antiradical [96] and catalytic performance [97, 98]. Additionally, 3D spongin-based scaffolds are reported as a support for enzyme adsorption. They were used in fixed-bed reactors for rapeseed oil transesterification and $100 \%$ conversion of the triglycerides to FAME and glycerol [99], or bisphenol biodegradation [100].

A relatively high resistance to acids and thermostability of spongin (even up to $260{ }^{\circ} \mathrm{C}$ ) $[88,101]$ indicate that spongin-based scaffolds with 3D architecture can be used in such novel scientific disciplines as Extreme Biomimetics $[78,102]$ in order to develop novel advanced composite materials. From this point of view, spongin-based scaffolds can be used as structural templates in the solvothermal synthesis reactions aimed at developing novel $\mathrm{Fe}_{2} \mathrm{O}_{3}-$ [101]; $\mathrm{MnO}_{2}$ - [103] and $\mathrm{TiO}_{2}$-based [104] composites for electrochemical and catalytic applications. Recently, Petrenko et al. [102], for the first time, have carbonized the spongin scaffolds at $1200{ }^{\circ} \mathrm{C}$. Intriguingly, the resulting carbon sponge resembles the shape of the original spongin scaffold, but uniquely preserves the nano-structural features of collagen triple-helix and; as a result, it is so stable that it can be cut into any shape with a metal saw. Coated with a metal layer, it becomes a unique composite material with excellent catalytic performance [102].

\section{Conclusions}

Both bioinspired materials science and biomimetics represent modern scientific niches, studying natural and artificial phenomena that possess high technological potential. These disciplines were born at the crossroads between biomineralogy, zoology, physiology, biochemistry, structural biology, physics, biomechanics, chemistry and classical materials science. Nowadays, biomimetics is well on track as a powerful approach for the generation of new ideas how to create composite materials using naturally occurring phenomena including those observed in marine invertebrates. Recently, marine biomimetics of sponges has gained enormous attention, especially from the perspective of being used in the development of novel, advanced, functional materials of 3D morphology and nanostructural, but hierarchical organization. Sponges as ancient organisms were able to modify their local aquatic microenvironment to create appropriate physicochemical conditions for the precipitation of silica. Consequently, their survival has been linked to producing unique silica-based 3D skeletal constructs with environmentally approved architecture. Intriguingly, structural motifs that can be found in glass sponges skeletal frameworks ideally resemble the morphology of mineral-free chitin- and spongin-based natural scaffolds. These structures represent interesting alternative to artificially produced scaffolds especially those made of plastics and similar synthetic polymer materials. Perspectives of practical applications of the 3D scaffolds of poriferan origin, represented in this review, will stimulate further development of sponges related farming worldwide. The renewability of sponges as large-scale source of these scaffolds remains to be the crucial point also in the future.

Acknowledgments This work was financially supported by German Research Foundation (DFG) grant HE 394-3, SMWK Project 02010311 (Germany) and subsidy from the Ministry of Science and Higher Education, Poland to PUT (no. 0912/SBAD/2006). M.W. is thankful for financial support from Polish National Agency for Academic Exchange (PPN/BEK/2018/1/00071).

Author contributions: All authors read and approved the final manuscript. HE conceived idea for the article; writing, review and editing; supervision; founding acquisition. MW contributed to data analysis; writing-original draft preparation; and founding acquisition. DT, AV, YK, AF contributed to literature search \& data analysis. IP contributed to visualization and data analysis.

Open Access This article is licensed under a Creative Commons Attribution 4.0 International License, which permits use, sharing, adaptation, distribution and reproduction in any medium or format, as long as you give appropriate credit to the original author(s) and the source, provide a link to the Creative Commons licence, and indicate if changes were made. The images or other third party material in this article are included in the article's Creative Commons licence, unless indicated otherwise in a credit line to the material. If material is not included in the article's Creative Commons licence and your intended use is not permitted by statutory regulation or exceeds the permitted use, you will need to obtain permission directly from the copyright holder. To view a copy of this licence, visit http://creativecommons.org/licenses/by/4.0/. 


\section{References}

1. M. Wysokowski, T. Machalowski, I. Petrenko, C. Schimpf, D. Rafaja, R. Galli, J. Ziętek, S. Pantović, A. Voronkina, V. Kovalchuk, V.N. Ivanenko, B.W. Hoeksema, C. Diaz, Y. Khrunyk, A.L. Stelling, M. Giovine, T. Jesionowski, H. Ehrlich, Mar. Drugs 18(2), 123 (2020)

2. H. Ehrlich, Marine Biological Materials of Invertebrate Origin (Springer, Cham, 2019)

3. H. Ehrlich, K. Demadis, O. Pokrovsky, P. Koutsoukos, Chem. Rev. 110, 4656-4689 (2010)

4. H. Ehrlich, M. Wysokowski, S. Żółtowska-Aksamitowska, T. Jesionowski, Mar. Drugs 16, 79 (2018)

5. T. Jesionowski, M. Norman, S. Żółtowska-Aksamitowska, I. Petrenko, Y. Joseph, H. Ehrlich, Mar. Drugs 16, 88 (2018)

6. H. Ehrlich, E. Brunner, P. Simon, V.V. Bazhenov, J.P. Botting, K.R. Tabachnick, A. Springer, K. Kummer, D.V. Vyalikh, S.L. Molodtsov, M. Kammer, H. Worch, A.V. Kovalev, S.N. Gorb, P. Koutsoukos, A. Summers, Adv. Funct. Mater. 21, 3473-3481 (2011)

7. M. Wysokowski, T. Jesionowski, H. Ehrlich, Am. Mineral. 103, 665-691 (2018)

8. L. Li, C. Guo, Y. Chen, Y. Chen, Bioinspir. Biomim. 15, 036006 (2020)

9. H.M. Reiswig, in Systema Porifera, ed. by J.N.A. Hooper, R.W.M. Van Soest, P. Willenz (Springer, Boston, 2002)

10. K.R. Tabachnick, L. Menshenina, A. Pisera, H. Ehrlich, Zootaxa 2883, 1-22 (2011)

11. K.R. Tabachnick, J. Fromont, H. Ehrlich, L. Menschenina, Zootaxa 4664, 47-82 (2019)

12. J. Aizenberg, V.C. Sundar, A.D. Yablon, J.C. Weaver, G. Chen, Proc. Natl. Acad. Sci. USA 101, 3358-3364 (2004)

13. K.R. Brown, D. Bacheva, R.S. Trask, J. R. Soc. Interface 16 20180965 (2019)

14. G. Mayer, Science 310, 1144 (2005)

15. M.A. Monn, H. Kesari, Sci. Rep. 7, 39547 (2017)

16. M.A. Monn, H. Kesari, J. Mech. Behave. Biomed. Mater. 76, 69-75 (2017)

17. V. Schoeppler, E. Reich, J. Vacelet, M. Rosenthal, A. Pacureanu, A. Rack, P. Zaslansky, E. Zolotoyabko, I. Zlotnikov, Sci. Adv. 3, eaao2047 (2017)

18. M.A. Monn et al., Nat. Commun. 11, 373 (2020)

19. H. Ehrlich, A.V. Ersekovsky, A.L. Drosdov, D.R. Krylova, T. Hanke, H. Meissner, S. Heinemann, H. Worch, Russ. J. Mar. Biol. 32, 186-193 (2006)

20. H. Ehrlich, S. Heinemann, C. Heinemann, P. Simon, V.V. Bazhenov, N.P. Shapkin, R. Born, K.R. Tabachnick, T. Hanke, J. Nanomater. 2008, 53 (2008)

21. S. Heinemann, C. Heinemann, H. Ehrlich, M. Meyer, H. Baltzer, H. Worch, T. Hanke, Adv. Eng. Mater. 9, 1061-1068 (2007)

22. S. Heinemann, H. Ehrlich, C. Knieb, T. Hanke, Int. J. Mater. Res. 98, 603-608 (2007)

23. W.E.G. Müller, U. Schloßmacher, C. Eckert, A. Krasko, A. Boreiko, H. Ushijima, S.E. Wolf, W. Tremel, I.M. Müller, H.C. Schröder, Eur. J. Cell Biol. 86, 473-487 (2007)

24. K. Shimizu, T. Amano, M.R. Bari, J.C. Weaver, J. Arima, N. Mori, Proc. Natl. Acad. Sci. 112, 11449-11454 (2015)

25. H. Ehrlich et al., Nat. Chem. 2, 1084-1088 (2010)

26. H. Ehrlich et al., J. Exp. Zool. 308B, 473-483 (2007)

27. H. Ehrlich et al., Adv. Opt. Mater. 4, 1608-1613 (2016)

28. A. Inayat, J. Schwerdtfeger, H. Freund et al., Chem. Eng. Res. 66, 2758-2763 (2011)

29. A. Della Torre et al., Comput. Chem. Eng. 92, 55-63 (2016)
30. M. Frey, T. Romero, A.C. Roger, D. Edouard, Catal. Today 273, 83-90 (2016)

31. L. Fratalocchi, G. Groppi, C.G. Visconti, L. Lietti, E. Tronconi, Chem. Eng. J. 386, 123988 (2020)

32. F.B. Löffler, F.J. Altermann, E.C. Bucharsky, K.G. Schell, M.L. Vera, H. Triad, A. Dwojak, M.I. Litter, Int. J. Appl. Ceram. Technol. 00, 1-10 (2020)

33. A. Alvarez, J.M. Sieben, M.M.E. Duarte, ChemCatChem 9, 853 (2017)

34. V. Middelkoop, A. Vamvakerso, D. de Wit, S.D.M. Jacques, S. Danaci, C. Jacquot, Y. de Vos, D. Matras, S.W.T. Price, A.M. Beale, J. CO2 Util. 33, 478-487 (2019)

35. V.C. Sundar, A.D. Yablon, J.L. Grazul, M. Ilan, J. Aizenberg, Nature 424, 899-900 (2003)

36. Y. Kul'chin, S.S. Voznesenski, O.A. Bukin, A.V. Bezverbny̌̆, A.L. Drozdov, I.G. Nagorny, A.N. Galkina, Opt. Spectrosc. 107, 442 (2009)

37. N. Buchtova et al., J. Mat. Sci. Mater. Med. 24, 1875-1884 (2013)

38. S. Heinemann, T. Coradin, M.F. Desimone, Biomater. Sci. 1, 688-702 (2013)

39. F. Baiano, C. Vitale-Brovarone, J. Biomed. Mater. Res. 97A, 514-535 (2011)

40. E. Martins, M.S. Rocha, T.H. Silva, R.L. Reis, in Marine-Derived Biomaterials for Tissue Engineering Applications, ed. by A. Choi, B. Ben-Nissan (Springer, Singapore, 2019)

41. S. Sageghzade et al., Mat. Sci. Eng. C 71, 431-438 (2017)

42. H.-Y. Mi, X. Jing, B.N. Napowicki, Z.T. Li, L.S. Turng, H.X. Huang, Chem. Eng. J. 331, 652-662 (2018)

43. S. Heinemann, C. Heinemann, S. Wenish, V. Alt, H. Worch, T. Hanke, Acta Biomater. 9, 4878-4888 (2013)

44. S. Nikolov, M. Petrov, L. Lymperakis, M. Friák, C. Sachs, H.-O. Fabritius et al., Adv. Mater. 22, 519-526 (2010)

45. H. Ehrlich, Int. Geol. Rev. 52(7), 661-699 (2010)

46. B. Duan, Y. Huang, A. Lu, L. Zhang, Prog. Polym. Sci. 82, 1-33 (2018)

47. T. Machałowski, M. Wysokowski, M.V. Tsurkan et al., Molecules 24(20), 3736 (2019)

48. T. Machałowski, M. Wysokowski, S. Żółtowska-Aksamitowska, N. Bechmann et al., Carbohyd. Polym 226, 115301 (2019)

49. M. Kaya, M. Mujtaba, H. Ehrlich et al., Carbohydr. Polym. 176, 177-186 (2017)

50. G. Crini, Environ. Chem. Lett. 17, 1623-1643 (2019)

51. A. Anitha, S. Sowmya, P.T.S. Kumar et al., Prog. Polym. Sci. 39, 1644-1667 (2014)

52. Y. Fang, Y. Hu, Z. Wang et al., Chem. Eng. J. 388, 124169 (2020)

53. J.L. Shamshina, P. Berton, D. Rogers, ACS Sustain. Chem. Eng. 7, 6444-6457 (2019)

54. X. Zhang, M. Rolandi, J. Mater. Chem. B 5, 2547-2559 (2017)

55. T. Philbert, B.H. Lee, N. Fabien, Appl. Biochem. Biotechnol. 181, 1314-1337 (2017)

56. H. Ehrlich, M. Maldonado, K.D. Spindler et al., J. Exp. Zool. 308B, 347-357 (2007)

57. H. Ehrlich, J.K. Rigby, J.P. Botting et al., Sci. Rep. 3, 17-20 (2013)

58. H. Ehrlich, O.V. Kaluzhnaya, E. Brunner et al., J. Struct. Biol. 183, 474-483 (2013)

59. H. Ehrlich, O.V. Kaluzhnaya, M.V. Tsurkan et al., Proc. R. Soc. B 280, 20130339 (2013)

60. E. Brunner et al., J. Struct. Biol. 168, 539-547 (2009)

61. H. Ehrlich et al., Int. J. Biol. Macromol. 47, 132-140 (2010)

62. H. Ehrlich et al., Int. J. Biol. Macromol. 104, 1706-1712 (2017)

63. H. Ehrlich et al., PLoS ONE 13, e0195803 (2018)

64. S. Żółtowska-Aksamitowska, M.V. Tsurkan, S.C. Lim et al., J. Biol. Macromol. 112, 1021-1028 (2018) 
65. S. Żółtowska-Aksamitowska, L.A. Shaala, D.T.A. Youssef et al., Mar. Drugs 16, 1-17 (2018)

66. M. Wysokowski et al., Int. J. Biol. Macromol. 62, 94-100 (2013)

67. L.A. Shaala, H.Z. Asfour, D.T.A. Youssef et al., Mar. Drugs 17, $92(2019)$

68. J. Vacelet, D. Erpenbeck, C. Diaz, H. Ehrlich, J. Fromont, Zool. Anz. 280, 14-20 (2019)

69. C. Klinger, S. Żółtowska-Aksamitowska, M. Wysokowski et al., Mar. Drugs 17, 131 (2019)

70. J. Fromont, S. Żółtowska-Aksamitowska, R. Galli et al., Zool. Anz. 280, 21-29 (2019)

71. V. Mutsenko, O. Gryshkov, O. Rogulska, A. Lode, A.Y. Petrenko, M. Gelinsky, B. Glasmacher, H. Ehrlich, in Marine-derived biomaterials for tissue engineering applications, ed. by A. Choi, B. Ben-Nissan (Springer, Singapore, 2019)

72. V.V. Mutsenko, V.V. Bazhenov, O. Rogulska et al., Int. J. Biol. Macromol. 104, 1966-1974 (2017)

73. V.V. Mutsenko, O. Gryshkov, L. Lauterboeck et al., Int. J. Biol. Macromol. 104, 1955-1965 (2017)

74. B. Binneweg et al., Mater. Sci. Eng. C 109, 110566 (2020)

75. M. Schubert et al., Int. J. Mol. Sci. 20, 5105 (2019)

76. M. Wysokowski, I. Petrenko, A.L. Stelling, D. Stawski, T. Jesionowski, H. Ehrlich, Polymers 7, 235-265 (2015)

77. H. Ehrlich et al., J Mater Chem B 1(38), 5092-5099 (2013)

78. H. Ehrlich, Extreme Biomimetics (Springer International Publishing, Cham, 2017)

79. M. Wysokowski et al., Mater. Sci. Eng. C 33, 3935-3941 (2013)

80. M. Wysokowski et al., RSC Adv. 4, 61743-61752 (2015)

81. M. Wysokowski et al., Nano Res. 8, 2288-2301 (2018)

82. M. Wysokowski et al., Int. J. Biol. Macromol. 78, 224-229 (2015)

83. M. Wysokowski et al., Mat. Chem. Phys. 188, 115-124 (2017)

84. A. Sorushanova, L.N. Delgado, Z. Wu, N. Shologu, A. Kshisagar, R. Ragunath, A.M. Mullen, Y. Bayon, A. Pandit, M. Raghunath, D.I. Zeugolis, Adv. Mater. 31, 1801651 (2018)

85. S. Ling, W. Chen, Y. Fan, K. Zheng, K. Jin, H. Yu, M.J. Buehler, D.L. Kaplan, Biopolymer nanofibrils: Structure, modeling, preparation, and applications. Prog. Polym. Sci. 85, 1-56 (2018)

86. S. Ling, D.L. Kaplan, M.J. Buehler, Nanofibrils in nature and materials engineering. Nat. Rev. Mater. 3, 18016 (2018)

87. S.-W. Chang, M.J. Buehler, Molecular biomechanics of collagen molecules. Mater. Today 17, 70-76 (2014)
88. T. Szatkowski, T. Jesionowski, in Extreme Biomimetics, ed. by H. Ehrlich (Springer International Publishing, Cham, 2017)

89. D. Green, D. Howard, X. Yang, M. Kelly, R.O.C. Oreffo, Tissue Eng. 9(6), 1159-1166 (2003)

90. R.O.C. Oreffo, A.S. Virdi, J.T. Triffit, Eur. J. Cell Biol. 74, 251 (1997)

91. M.-M. Kim, E. Mendis, N. Rajapakse, S.-H. Lee, S.-K. Kim, J. Biomed. Mater. Res. 90(2), 540-546 (2009)

92. E. Cunningham, N. Dunne, G. Walker et al., J. Mater. Sci. Mater. Med. 21, 2255-2261 (2010)

93. E. Boccardi, I.V. Belova, G.E. Murch, A.R. Boccacini, T. Fiedler, J. Mater. Sci. Mater. Med. 26, 200 (2015)

94. J.R. Parisi, K.R. Fernandes, I.R. Avanzi et al., Mar Biotechnol 21, 30-37 (2019)

95. K.R. Fernandes, J.R. Parisi, A.M.P. Magri et al., J. Mater. Sci. Mater. Med. 30, 64 (2019)

96. M. Normann, P. Bartczak, J. Zdarta, W. Tomala, B. Żurańska, A. Dobrowolska, A. Piasecki, K. Czaczyk, H. Ehrlich, T. Jesionowski, Int. J. Mol. Sci. 17(10), 1564 (2016)

97. M. Normann, J. Zdarta, P. Bartczak, A. Piasecki, I. Petrenko, H Ehrlich, T. Jesionowski Open Chem 14, 243-254 (2016)

98. M. Norman, S. Żółtowska-Aksamitowska, A. ZgołaGrześkowiak, H. Ehrlich, T. Jesionowski, J. Hazard. Mater. 347, 78-88 (2018)

99. J. Zdarta, M. Norman, W. Smułek, D. Moszyński, E. Kaczorek, A.L. Stelling, H. Ehrlich, T. Jesionowski, Catalysts 7, 147 (2017)

100. J. Zdarta, K. Antecka, R. Frankowski, A. Zgoła-Grześkowiak, H. Ehrlich, T. Jesionowski, Sci. Total Environ. 615, 784-795 (2018)

101. T. Szatkowski et al., RSC Adv. 5, 79031-79040 (2015)

102. I. Petrenko, A. Summers, P. Simon, S. Żółtowska-Aksamitowska, M. Motylenko, C. Schimpf et al., Sci. Adv. 5, eeax2805 (2019)

103. T. Szatkowski et al., Nano Res. 11(8), 4199-4214 (2018)

104. T. Szatkowski, K. Siwińska-Stefańska, M. Wysokowski, A.L. Stelling, Y. Joseph, H. Ehrlich, T. Jesionowski, Biomimetics 2, 4 (2017)

Publisher's Note Springer Nature remains neutral with regard to jurisdictional claims in published maps and institutional affiliations. 